\title{
ESTUDO DA OCORRÊNCIA DE "DOR CRÔNICA” EM IDOSOS DE UMA COMUNIDADE ATENDIDA PELO PROGRAMA SAÚDE DA FAMÍLIA EM GOIÂNIA
}

\author{
STUDY OF THE OCCURRENCE OF "CHRONIC PAIN" IN ELDERY OF A COMMUNITY ASSISTED BY THE \\ HEALTH FAMILY PROGRAM IN GOIÂNIA
}

ESTUDIO DE LA OCURRENCIA DEL "DOLOR CRÓNICO" EN LOS ANCIANOS DE UNA COMUNIDAD AYUDADAS POR EL PROGRAMA SALUD DE LA FAMILIA EN GOIÂNIA

\author{
Patrícia Ferreira Lacerda ${ }^{1}$ \\ Lorany Ferreira de Godoy ${ }^{2}$ \\ Milene Gonçalves Cobianchi ${ }^{3}$ \\ Maria Márcia Bachion ${ }^{4}$
}

\begin{abstract}
RESUMO: Esta pesquisa descritiva objetivou analisar a ocorrência de dor crônica (NANDA, 2002) em idosos de uma comunidade em Goiânia (GO). A amostra consistiu de 40 idosos dos 102 cadastrados numa equipe do Programa de Saúde da Família. A coleta de dados ocorreu de janeiro a junho de 2004, no domicílio dos idosos. Foi utilizado um protocolo que incluiu entrevista, exame clínico, escalas de avaliação de dor e de depressão. Foi identificada dor crônica em 25 idosos $(62,5 \%)$. A intensidade da dor relatada foi predominantemente de intensidade insuportável $(36 \%)$ e leve $(28 \%)$, vindo a seguir a intensidade moderada $(20 \%)$ e intensa $(16 \%)$. A localização da dor foi predominantemente a região dorsal (48\%), seguida dos membros inferiores (24\%). O agente lesivo biológico foi o fator relacionado mais freqüente. As características definidoras presentes em mais de $50 \%$ da amostra foram: relato verbal ou codificado (100\%); capacidade alterada de continuar atividades prévias $(68 \%)$; mudanças no padrão de sono (48\%) e fadiga (52\%). A dor crônica configurou-se um diagnóstico freqüente em idosos, com múltiplas características definidoras que dão sustentação segura à sua afirmação. Os fatores relacionados geralmente se referem ao processo de envelhecimento mal sucedido ou patologias características desta faixa etária.
\end{abstract}

PALAVRAS CHAVES: Diagnóstico de enfermagem; Dor; Saúde do Idoso.

ABSTRACT: The aim of this descriptive research was to analyze the chronicle pain (NANDA, 2002) in old people of a community in Goiânia (GO). A group of 40 old people from 102 registered ones in a Family Health Program composed the sample. The data were collect from January to June of 2004, at the old people residences. The procedures of data collect consisted by an interview, a physical examination, both pain and depression valuation scales. It was identified chronicle pain in $62.5 \%$ of the old people. The pain intensity related was predominantly unsupportable $(36 \%)$ and slight $(28 \%)$, followed by the moderated $(20 \%)$ and intense $(16 \%)$. The pain place was mainly in the dorsal region (48\%), and, then, in the inferior members $(24 \%)$. The biologic injurious agents were the most frequent related factor. The defining characteristics present in more $50 \%$ of the sample were: verbal report or codified $(100 \%)$; modified capacity of continuing previous activities $(68 \%)$; changes on the sleeping pattern $(48 \%)$ and tiredness $(52 \%)$. The chronicle pain is a frequent diagnosis in old people with multiple defining characteristics that maintain the affirmation steady. The relation factors generally refer to the unsuccessful aging process or to the pathologies characteristic of this age range.

KEY-WORDS: diagnosis; pain, nursing, aged; family health program.

RESUMEN: Este estudio descriptivo objetivo analizar la ocurrencia de dolor crónico (NANDA, 2002) en ancianos de una comunidad en Goiânia (GO). La muestra consistió de 40 ancianos de los 102 catastrados en un equipo del Programa de Salud de la Familia. A recolecta de datos ocurrió de enero a junio de 2004, en el domicilio de los ancianos. Constó de la aplicación de un protocolo que incluyó entrevista, examen clínico, escalas de evaluación de dolor y de depresión. Fue identificado dolor crónica en un $62,5 \%$ de los ancianos. La intensidad del dolor relatado fue predominantemente de intensidad insoportable (un $36 \%$ ) y leve (un $28 \%$ ), viniendo a continuación la intensidad moderada (un 20\%) e intensa (un 16\%). La localización del dolor fue predominantemente la región dorsal (un 48\%), seguida de los miembros inferiores (un 24\%). El factor relacionado agente lesivo biológico el más frecuente. Las características definidoras presentes en más del $50 \%$ de la muestra fueron relato verbal o codificado (un 100\%); capacidad alterada de continuar actividades previas (un 68\%); cambios en el patrón de sueño (un $48 \%$ ) y fatiga (un $52 \%$ ). El dolor crónica se configuró un diagnóstico frecuente en ancianos, con múltiplas características definidoras que dan sustentación segura a la su afirmación. Los factores relacionados básicamente se refieren al proceso de envejecimiento mal sucedido o patologías características de los ancianos.

TERMINOS CLAVES: Diagnóstico de Enfermería; Dolor; Salud del Anciano. 


\section{INTRODUÇÃO}

O organismo humano, desde sua concepção até a morte, passa por diversas fases: desenvolvimento, puberdade, maturidade ou estabilização e envelhecimento. Nessas fases é possível identificar marcadores físicos e fisiológicos de transição. O envelhecimento manifesta-se por declínio das funções dos diversos órgãos que, caracteristicamente, tendem a ser lineares em função do tempo, não se conseguindo definir um ponto exato de transição, como nas demais fases. Tem início ao final da segunda década da vida, perdurando por longo tempo, sendo pouco perceptível, até que surjam, no final da terceira década, as primeiras alterações funcionais e/ou estruturais atribuídas ao envelhecimento (PAPALÉO NETTO, 1999).

Não existe um só envelhecer, mas processos de envelhecimento - de gênero, etnia, de classe social, de cultura, determinados socialmente (CARVALHO FILHO, 1999).

Há divergências quanto ao ponto de corte para indicar o estado de velhice. A maioria dos estudiosos das áreas de gerontologia e geriatria adotam os 65 anos de idade. Este é o critério adotado pela Organização das Nações Unidas para os países desenvolvidos. Para os países em desenvolvimento, onde a expectativa média de vida é menor, 60 anos como a idade é entendida como de transição das pessoas para o segmento idoso da população. A Assembléia Mundial sobre Envelhecimento, ocorrida em 1982, na cidade de Viena, Áustria, definiu população idosa como o grupo de pessoas com 60 anos e mais (PASCHOAL, 1999).

Para o atendimento de idosos, o enfermeiro pode utilizar diferentes metodologias, entre elas destacamos o processo de enfermagem, que pode ser compreendido como a utilização de cinco etapas sistematizadas, interdependentes, que são: coleta de dados, diagnóstico de enfermagem, planejamento da assistência de enfermagem, implementação da assistência de enfermagem e avaliação.

A enfermagem tem contribuído para o desenvolvimento do conhecimento na área da saúde do idoso com alguns estudos voltados para a preconização de ações na modalidade de soluções de problemas de modo geral (SÁ, 1997; MORAIS, BRAGA \& SILVA, 1995) nas quais são destacados a assistência de Enfermagem no processo patológico e na resolução dos problemas de saúde do indivíduo idoso; outros focalizam planos de cuidados (CANTERA \& DOMINGO, 2000; PACHECO, 1997) destacando o cuidado a partir da elaboração de um plano de assistência. Atualmente busca-se aplicar todas as fases do Processo de Enfermagem (ARAÚJO et al 2002; SANTANA et al, 2000; BACHION et al, 2000; BACHION et al, 1999; BERGER \& MAILLOUXPOIRIER, 1995; CRUZ, 1990).

Mesmo considerando que envelhecer e adoecer não sejam sinônimos, não podemos ignorar que determinadas enfermidades são mais freqüentes em idosos, necessitando, portanto, maiores investimentos no atendimento de enfermagem. Um dos problemas mais comuns nesta população são os quadros de dor crônica (GATTO, 1999).

A dor crônica é descrita como uma dor que dura meses, anos, ou a vida toda. Pode haver ocorrências intermitentes de dor crônica que se caracterizam por períodos de dor, intercalados com intervalos isentos de dor. Esse padrão pode repetir-se continuamente durante anos. A dor crônica também pode ser constante, persistir e piorar progressivamente, apesar do tratamento (ATKINSON \& MURRAY, 1989).

A dor crônica é definida segundo a North American Nursing Diagnosis Association (NANDA, 2002), como sendo uma:

\section{"experiência sensorial e emocional desagradável que surge de lesão tissular real ou potencial ou descrita em termos de tal lesão (Associação Internacional para o Estudo da Dor); início súbito ou lento, de intensidade leve a intensa, constante ou recorrente, sem um término antecipado ou previsível e com duração de mais de seis meses" (p.100).}

A dor crônica é considerada um evento complexo, de natureza biopsicossocial, que se configura em problema de saúde coletiva e exige abordagem multidisciplinar (RULL, 2004).

Tanto a dor aguda (com duração menor de seis meses) como a crônica podem ser classificadas em nociceptiva, neuropática, mista e psicogênica.

A dor nociceptiva começa simultaneamente ao início da atividade do fator causal, o qual pode ser usualmente identificado. São exemplos de dor nociceptiva a dor secundária a agressões externas (picada de um inseto, fratura de um osso, corte da pele), a dor visceral (cólica renal, apendicite), a neuralgia do trigêmio, a dor da artrite e da invasão neoplásica dos ossos (PORTO, 2000; BLACK \& MATASSARIN-JACOBS, 1996).

A dor nociceptiva pode ser espontânea se expressa com as mais variadas designações: pontada, facada, aguda, rasgando, latejante, surda, contínua, profunda, vaga, dolorimento. Todas essas denominações sugerem lesão tissular. Pode ser evocada se desencadeada por algumas manobras, tais como: manobra de Lasègue na ciatalgia (dor provocada pelo estiramento da raiz nervosa, obtida pela elevação do membro inferior afetado, estando o indivíduo em decúbito dorsal); lavar o rosto e escovar os dentes, nos idosos com neuralgia do trigêmio. A dor evocada reproduz a dor sentida pelo idoso (PORTO, 2000; BLACK \& MATASSARIN-JACOBS, 1996).

A dor neuropática decorre de lesão do sistema nervoso periférico ou central. Sua etiologia é variada, incluindo afeç̧ões traumáticas, inflamatórias, vasculares, infecciosas, neoplásicas, degenerativas, desmielinizantes e iatrogênicas. $O$ início pode coincidir com a atuação do fator causal, porém mais comumente, ocorre após dias, semanas, meses ou mesmo anos. A dor neuropática apresenta-se com 
pelo menos um dos seguintes elementos: constante, intermitente (ambos são espontâneos) e evocado. A dor constante está presente em praticamente 100\% dos casos, sendo usualmente descrita como dor em queimação ou como dor dormente ou em formigamento. Trata-se de uma disestesia (sensação anormal desagradável), normalmente nunca experimentada pelo idoso (PORTO, 2000; BLACK \& MATASSARIN-JACOBS, 1996).

A dor intermitente é mais freqüente nas lesões nervosas periféricas e da medula espinhal, sendo rara nas lesões encefálicas e relatada como dor em choque, aguda. Lembra a dor da ciatalgia, mas diferentemente desta, seu trajeto não segue o de qualquer nervo (PORTO, 2000; BLACK \& MATASSARIN-JACOBS, 1996).

A dor evocada, presente em mais da metade dos casos de dor neuropática, embora seja mais comum nas lesões encefálicas, é também freqüente nas lesões medulares e do sistema nervoso periférico, se deve aos rearranjos sinápticos decorrentes da desaferentação podendo manifestar-se sob a forma de alodínia (é uma sensação desagradável, dolorosa, provocada pela estimulação tátil leve, de uma área com limiar de excitabilidade aumentado -área desaferentada-) ou de hiperpatia (sensação desagradável mais dolorosa que o usual, provocado pela estimulação nóxica de uma área com limiar de excitabilidade aumentado - área desaferentada-) (PORTO, 2000; BLACK \& MATASSARIN-JACOBS, 1996).

A dor mista é aquela que decorre dos dois mecanismos anteriores. Ocorre, por exemplo, em certos casos de dor por neoplasia maligna, quando a dor se dá tanto ao excessivo estímulo dos nociceptores quanto a destruição das fibras nociceptiva (PORTO, 2000).

\section{AVALIAÇÃO DA DOR EM IDOSOS}

Poderíamos supor que os idosos se queixam muito mais de dor do que os indivíduos mais jovens, sendo, inclusive, rotulados de poliqueixosos e hipocondríacos (PORTO, 2000), contudo, diversas condições favorecem para que os quadros de dor entre idosos passem desapercebidos. Muitas vezes as manifestações dolorosas nos idosos são atípicas e mal localizadas (DUARTE \& DIOGO, 2000; PORTO, 2000). Além disso, a resposta à dor no idoso pode ser de menor intensidade devido a acuidade e o tato reduzidos, alterações nas vias neurais e menor processamento dos dados sensoriais (SMELTZER \& BARE, 1998).

A comunicação da dor pelos idosos aos familiares e aos profissionais que os assistem pode estar prejudicada por disfunções cognitivas, concomitância de outras doenças, extrema fragilidade física, depressão, alterações na audição e na fala, conceito pessoal e dos que o cercam de que a dor é "normal" na velhice, de que seja inalienável à doença, de que não é possível ou é muito difícil controlá-la e pelo desejo de não incomodar o cuidador (DUARTE \& DIOGO, 2000).

Deve-se pensar na coleta de informações sobre dor como um processo, que pode ser mais ou menos completo, ser realizado em etapas, apresentar maior ou menor grau de especificidade, dependendo do idoso, dos objetivos e filosofia da instituição (CRUZ \& PIMENTA, 1999). A avaliação da dor realizada uma única vez ou muito esporadicamente é de validade limitada. A identificação dos fatores que precipitam ou intensificam a dor são, muitas vezes, pouco valorizados pelos profissionais. Certas atividades, posições, mudanças de tempo, hora do dia, humor ou tipo de pensamento são comumente associadas com variações na dor. Embora não seja possível eliminar todos os fatores que possam agravar a queixa dolorosa, é desejável identificá-los e tê-los como parte do esquema de alívio da dor (DUARTE \& DIOGO, 2000).

A intensidade é, sem dúvida, o aspecto mais saliente da dor. Deve ser avaliada no momento da entrevista, quando ela está pior e melhor. Deste modo, profissionais e cuidadores terão idéia da variação da magnitude da queixa álgica (CRUZ \& PIMENTA, 1999).

Os métodos para a avaliação da dor são basicamente inferenciais e, em idosos, com condições de compreensão e verbalização adequadas, o autorelato é a chave para a afirmação diagnóstica. Nenhum instrumento de coleta de dados será totalmente completo ou totalmente isento de questões eventualmente desnecessárias. Cabe ressaltar que a educação formal e informal, a inteligência, o raciocínio lógico, entre outros fatores, e as habilidades afetivas do profissional (compromisso, motivação para atender e empatia com o idoso) são fundamentais para o uso adequado de qualquer instrumento. Quando o idoso está acompanhado por seu cuidador ou familiar, cada um individualmente e a interação de ambos devem ser observadas continuamente. $O$ idoso deve ser conduzido a relatar os seus comportamentos quando sente dor (CRUZ \& PIMENTA, 1999).

Em nossa atuação junto a esta população percebemos que os relatos de dor são freqüentes e nem sempre associados à patologia pré-existente. São comuns as queixas de dor nas pernas e na região lombar com duração de anos e até mesmo décadas.

Existem poucos estudos epidemiológicos sobre dor na população e, em especial, nos idosos. Os estudos diferem no período de cobertura, na classificação das síndromes crônica e na caracterização da queixa álgica o que os torna difíceis de serem comparados. Os achados sobre a freqüência de ocorrência de dor crônica em idosos variam entre 20\% a 88\% (DUARTE \& DIOGO, 2000).

Em nosso contexto de atendimento em saúde na cidade de Goiânia ainda não foram realizados levantamentos desta problemática em idosos, nesse sentido, propomos esta pesquisa, acreditando que os resultados obtidos podem contribuir para o planejamento de ações interdisciplinares de saúde, bem como gerar informações para direcionar 
pesquisas futuras e despertar para a necessidade de qualificação de pessoal na área.

\section{OBJETIVOS}

Frente ao exposto, nos propomos a realizar o presente estudo com o objetivo de estudar a ocorrência de dor crônica em idosos de uma comunidade em Goiânia (GO). Constituíram objetivos específicos:

1. Identificar a freqüência de dor crônica, sua intensidade e localização em idosos de uma comunidade em Goiânia;

2. Analisar os fatores relacionados $e$ características definidoras para dor crônica identificados nesta população.

\section{MÉTODO}

Trata-se de um estudo descritivo transversal. A população constou de 102 pessoas com idade maior ou igual a 60 anos moradores do Jardim Mariliza em Goiânia (Região/ Distrito Sul), atendidos pela equipe 02 do Programa Saúde da Família. A escolha desta área de abrangência deveu-se ao fato dos pesquisadores terem 0 apoio da equipe de enfermagem e dos agentes comunitários do local, favorecendo o trabalho de campo.

Os pesquisadores contataram todos os moradores idosos por meio dos agentes comunitários da área de abrangência da equipe de saúde da família do local. Deixaram de ser incluídos aqueles que não estavam presentes no seu domicílio por duas vezes na ocasião da visita para formalização do convite para participar da pesquisa, além daqueles que se recusaram em participar. Assim, a amostra constou de 40 idosos.

O projeto de pesquisa foi aprovado pela Coordenação Colegiada do Programa Saúde da Família da Secretaria de Saúde de Goiânia e pelo Comitê de Ética da Universidade Federal de Goiás.

Foi consultada a listagem dos idosos cadastrados no PSF do Jardim Mariliza para agendamento de Visita Domiciliária para consulta dos sujeitos, quanto ao aceite em participar do estudo, mediante consentimento livre e esclarecido por escrito, sendo garantido sigilo e anonimato aos participantes.

Após aceite, foram agendados data e local para coleta de dados que foi realizada no período de janeiro a junho de 2004.

Para este estudo empregamos as duas primeiras fases do Processo de Enfermagem, ou seja, a Coleta de Dados e Diagnóstico de Enfermagem.

Utilizamos como instrumento de coleta de dados um protocolo de avaliação clínica (Anexo I), que foi construído a partir da revisão de literatura e que foi analisado por expertos, quanto à pertinência, abrangência e organização lógica dos itens, que compunham um check list de informações que permitiam a verificação da presença das características definidoras e fatores relacionados de dor crônica.
Mediante a identificação de uma ou mais características definidoras propostas pela NANDA (2002) para o diagnóstico em questão realizou-se o julgamento clínico para identificação do fator relacionado e para a tomada de decisão acerca da presença do diagnóstico dor crônica. Em caso de dúvida houve um processo de discussão do caso entre os pesquisadores, até alcançar o consenso.

Para elaboração do diagnóstico de enfermagem foram arrolados as respectivas características definidoras (evidências, sinais e sintomas) e fatores relacionados (fatores causais ou coadjuvantes) presentes em cada caso.

Cabe esclarecer que a NANDA (2002), considera como fator relacionado para dor crônica a presença de incapacidade física ou psicológica crônica. Conforme revisão da literatura, podemos perceber que esta incapacidade é decorrente da dor e não a sua causa. Assim adotamos os fatores relacionados desta Taxonomia para dor aguda, ou seja: agentes lesivos biológicos, químicos, físicos e ou psicológicos, por entender que os mesmos estão de acordo com a literatura especializada na área.

Para análise dos resultados utilizamos procedimentos de estatística descritiva, tais como freqüência simples e medidas de tendência central.

\section{APRESENTAÇÃO E ANÁLISE DOS RESULTADOS}

Dos participantes, 27 eram mulheres e 13 homens, na faixa etária de 60 a 86 anos, sendo 23 com 60 a 70 anos, 12 com 71 a 80 anos e 5 com 81 a 86 anos. Metade dos idosos (20 pessoas) era casada, vindo, a seguir, os viúvos (15), solteiros (03) e separados (02).Quanto à escolaridade, 23 participantes apresentavam ensino fundamental incompleto, 10 eram analfabetos, 03 possuíam ensino médio completo. O ensino fundamental completo, ensino profissionalizante, ensino superior incompleto e ensino superior completo foram identificados com 01 idoso cada.

Dos 40 idosos avaliados, identificamos 25 $(62,5 \%)$ que apresentaram dor crônica. Quanto à intensidade, segundo a escala de avaliação de copos, foi indicada dor leve por 07 participantes (28\%), dor moderada por $05(20 \%)$ deles, dor intensa por outros 04 idosos $(16 \%)$ e dor insuportável em 09 casos (36\%).

A localização da dor foi predominantemente na região dorsal $(48 \%)$, seguida dos membros inferiores (24\%), cabeça $(08 \%)$, membros superiores $(04 \%)$, hemicorpo direito e tórax anterior ( $08 \%$ cada um).

Como já foi dito anteriormente, a dor tem como fatores relacionados: agentes lesivos biológicos, físicos, químicos ou fatores psicológicos. Os mesmos podem apresentar-se de forma isolada ou combinada. Dezoito idosos (72\%) apresentaram apenas 01 dos fatores relacionados e sete (28\%) apresentaram 02 destes fatores. Nenhum idoso apresentou três ou mais fatores. Assim, para a amostra, a média aritmética foi igual a 1,28 fatores, a mediana e a moda igual a 01, o primeiro quartil igual a 01 e o terceiro quartil igual a 02. 
O fator relacionado agente lesivo biológico foi identificado em 25 idosos (100\%).

O envelhecimento está relacionado com a presença de múltiplas afecções crônicas que se manifestam principalmente por dor, tais como insuficiência coronária, osteoartrose com fraturas, artrite reumatóide, hérnia hiatal e outras (PORTO, 2000). Estas alterações, entre outras, podem levar à ocorrência de dor.

Entre os idosos da amostra, $12(48 \%)$ relataram doenças oesteomusculares (reumatismo, osteoporose, artrose, artrite, espondilite), que podem estar envolvidas na etiologia da dor referida na região dorsal e membros inferiores. Dezoito idosos $(72 \%)$ referem patologias relativas ao sistema cardiovascular (hipertensão arterial, história de acidente vascular cerebral, infarto do miocárdio, doença de Chagas, angina, trombose venosa profunda), seis (24\%) informam alterações do sistema endócrino (diabete, hipotireoidismo), oito (32\%) relatam labirintite e cinco (20\%) apresentam depressão. Outras doenças como alergia, doença de Parkinson, cálculo renal, gastrite também foram referidas.

É comum que o ser humano tenha pelo menos uma patologia crônico-degenerativa após os 60 anos de idade (LESSA, 1998), assim, além do desgaste do sistema osteomuscular inerente ao processo de envelhecimento (PORTO, 2000), esta população convive com muitas alterações que se configuram em fatores causais de dor.

Os fatores psicológicos foram identificados em 6 idosos (24\%).

A dor psicogênica não tem substrato orgânico, sendo inteiramente gerada, por mecanismos psíquicos. A dor tende a ser difusa, generalizada, imprecisa; às vezes, pode ser localizada e, nesses casos, a topografia da dor tende a corresponder à da imagem corporal que o idoso tem da estrutura que ele julga envelhecida. A intensidade da dor é variável, sendo agravada pelas condições emocionais, o que, via de regra, é contestado pelo idoso. Sinais e sintomas de depressão, ansiedade crônicas e utilização inadequada e abusiva de medicamentos são freqüentemente identificáveis (PORTO, 2000; BLACK \& MATASSARIN-JACOBS, 1996).

Para dar sustentação ao diagnóstico de enfermagem dor crônica, como já foi dito anteriormente, também levamos em consideração a presença de características definidoras, que são propostas em número de 16 pela NANDA (2002). Estes sinais e sintomas foram identificados nos idosos com uma variação de 1 a 12 , sendo a média aritmética igual a 5,12, a moda igual a 1 e 4 , a mediana igual a 5 , o primeiro quartil igual a 3 , o terceiro quartil igual a 7 .

A característica definidora relato verbal ou codificado, foi identificado em 25 idosos (Tabela 1). As respostas da pessoa que sofre a dor são individuais e influenciadas pelas constituições fisiológicas, psicológicas, culturais. De modo geral, estas respostas decorrentes da dor podem ser atenuadas, acentuadas ou perpetuadas. É indispensável a atitude de confiar nos relatos da pessoa que sofre dor para se trabalhar com eficiência (ATKINSON \& MURRAY, 1989).

Muitos idosos podem deixam de relatar as dores que estão sentindo por considerá-las como conseqüência inevitável do envelhecimento, acreditando que devem ser suportá-las sem queixas (PORTO, 2000). Contudo, como verificamos no presente estudo, ao ser dada a oportunidade de expressar-se sobre esta sensação, os idosos revelam positivamente esta ocorrência.

Tabela 1 - Distribuição das características definidoras de dor crônica em 25 idosos de uma comunidade de Goiânia (GO). Jan/jun. 2004

\begin{tabular}{lcc}
\hline Características definidoras & $n$ & $f$ \\
Relato verbal ou codificado & 25 & 100 \\
Capacidade alterada de continuar atividades prévias & 17 & 68 \\
Mudanças no padrão do sono & 12 & 48 \\
Fadiga & 13 & 52 \\
Irritabilidade & 11 & 44 \\
Depressão & 07 & 28 \\
Agitação & 07 & 28 \\
Mudança de peso & 07 & 28 \\
Medo de nova lesão & 08 & 32 \\
Atrofia do grupo muscular envolvido & 06 & 24 \\
Interação reduzida com as pessoas & 04 & 16 \\
Expressão facial & 03 & 12 \\
Resposta mediada pelo simpático & 03 & 12 \\
Foco em si próprio & 02 & 08 \\
Evidência observada de comportamento de defesa & 02 & 08 \\
Anorexia & 01 & 04 \\
\hline
\end{tabular}

A característica definidora capacidade alterada de continuar atividades prévias, foi identificada em 17 idosos (Tabela 1). Evitar a dor é uma necessidade humana básica. Embora uma pessoa possa sobreviver com dor, a sua presença contínua interfere no bemestar do indivíduo. $\mathrm{O}$ aumento da incapacidade e a invalidez podem interferir na possibilidade da pessoa 
continuar trabalhando ou manter algum papel positivo dentro da família. (ATKINSON \& MURRAY, 1989).

Mudanças no padrão do sono foram identificadas em 12 idosos (Tabela 1). A dor pode desorganizar o sono e diminuir o apetite, afetando desse modo, a necessidade básica do indivíduo em relação a repouso e nutrição (ATKINSON, MURRAY, 1989).

A fadiga foi identificada em 13 idosos, conforme mostra a Tabela 1. Trata-se de uma queixa extremamente comum no idoso e, tal como nos pacientes jovens, pode ser um sintoma de doença orgânica ou psíquica. A depressão é uma das causas mais comuns de fadiga nessa faixa etária e pode ser sua única manifestação (PORTO, 2000).

A irritabilidade foi identificada em 11 idosos e a agitação em sete, conforme pode ser observado na Tabela 1. A irritabilidade é advinda do fato da dor impedir a realização de tarefas, provocar desconforto físico e emocional. Como não tem resolução imediata acerca do seu problema o idoso sente-se sem autonomia sobre seu próprio corpo e vida, levando-o assim a um estado de irritação e estresse. A ansiedade no idoso com dor pode resultar da patologia de base e de toda gama de complicações e conseqüências dela advinda, da dor em si ou de ambas as situações (DUARTE \& DIOGO, 2000).

A depressão foi identificada em sete idosos (Tabela 1). Trata-se de uma das respostas emocionais mais freqüentes associadas à dor crônica, juntamente com a ansiedade (DUARTE \& DIOGO, 2000).

A depressão associa-se e agrava a vivência dolorosa. Quando não controlada, interfere significativamente na qualidade de vida do idoso, pois ocasiona maior comprometimento do sono, do humor, do apetite, maior queixa de fadigamento e apreciação negativa da vida e de si mesmo, maiores problemas no relacionamento interpessoal. Pode dificultar seriamente o tratamento e levar os idosos a aderirem menos à terapêutica e à obtenção de resultados menos satisfatórios no controle do quadro álgico (DUARTE \& DIOGO, 2000).

A característica definidora mudança de peso, foi identificada em sete idosos, como pode ainda ser visto na Tabela 1. O ser humano ganha peso dos 25 até por volta dos 60 anos, depois disso o peso tende a reduzirse em conseqüência da perda de massa óssea e muscular. Portanto, nos indivíduos muito idosos, a perda de peso deve ser mais valorizada quando ocorre em curto intervalo de tempo. Quando o paciente relata emagrecimento, é importante ter uma idéia de quantos quilos perdeu e em quanto tempo isso ocorreu (PORTO, 2000).

A atrofia do grupo muscular envolvido foi identificada em seis idosos. Uma dor persistente retarda a recuperação e produz uma condição incapacitante que provoca falta de atividade cujo resultado final é fraqueza e atrofia muscular. Essa falta de atividade pode agravar distúrbios do sono e do apetite já existentes (ATKINSON \& MURRAY, 1989).
O medo de nova lesão foi identificado em oito idosos. Novas lesões associam-se a possibilidade de outros episódios de dor ou agravamento da dor atual.

De acordo com a Tabela 1, podemos observar que a característica definidora resposta mediada pelo simpático que tem como sinais objetivos palidez, aumento da pressão arterial, aumento da pulsação, aumento das respirações, tensão dos músculos esqueléticos, dilatação das pupilas e diaforese, foi identificada em três idosos. As respostas simpáticas muitas vezes estão associadas a uma dor de intensidade baixa a moderada, ou a dor superficial. Isso significa que as defesas do organismo são mobilizadas e que se iniciou a resposta "lute ou fuja". (BLACK \& MATASSARIN-JACOBS, 1996).

$O$ foco em si próprio foi identificado em dois idosos. No caso deste processo ser intenso, pode haver desorganização de sua capacidade de se alimentar, de dormir ou de desempenhar atividades (ATKINSON \& MURRAY, 1989).

A interação reduzida com as pessoas também foi identificada em quatro idosos. Muitas pessoas com uma dor crônica interminável tornam-se retraídas e isoladas. Freqüentemente sua dor produz-lhes exaustão, tanto física quanto mental. A dor crônica está associada a retraimento e desespero (BLACK \& MATASSARIN-JACOBS, 1996).

A expressão facial de dor foi identificada em três idosos. A observação dos comportamentos de dor vocalização (choro, gemidos), expressão facial (contração muscular), movimento corporal (postura de proteção) - deve ser cautelosa, pois, na dor crônica, não há comportamento específico. Alguns autores afirmam que a mensuração de parâmetros biológicos (sinais vitais, entre outros) é mais utilizada na dor aguda, devido à adaptação das respostas neurovegetativas que ocorrem na dor crônica (DUARTE \& DIOGO, 2000).

A evidência observada de comportamento de defesa foi identificada em dois idosos. Assumir uma postura que minimiza a dor, como se deitar imóvel, defender-se, contrair as pernas ou assumir uma posição fetal, retrair-se quando tocado e segurar ou proteger a área dolorida são evidências de um comportamento de defesa (BLACK \& MATASSARINJACOBS, 1996). As respostas comportamentais não são diagnósticas de dor, porém podem proporcionar informações acerca de sua causa.

A anorexia foi encontrada em um idoso. A dor pode diminuir $\mathrm{o}$ apetite, afetando, desse modo, a necessidade básica do indivíduo em relação a nutrição. A dor crônica produz uma condição incapacitante que provoca falta de atividade. Essa falta de atividade pode agravar distúrbios do apetite já existentes (ATKINSON \& MURRAY, 1989).

A progressiva interferência da dor na fisiologia do indivíduo afetará, por sua vez, as suas necessidades em relação a amor, relacionamentos e auto-estima. O resultado é uma diminuição da autoestima. A dor persistente pode alterar os relacionamentos interpessoais, causar diminuição dos contatos sociais e, por fim, o isolamento. Assim sendo, 
torna-se evidente que a dor pode afetar necessidades psicológicas e fisiológicas do ser humano (ATKINSON \& MURRAY, 1989).

A assistência ao idoso deve prezar pela manutenção da qualidade de vida, considerando os processos de perdas próprias do envelhecimento e as possibilidades de prevenção, manutenção e reabilitação de seu estado de saúde (MARIN, BARBOSA \& TAKITANE, 2000).

A promoção da saúde pode ser definida como atividades que, pela acentuação do aspecto positivo, assiste a pessoa no sentido de desenvolver os recursos que irão manter ou aumentar o seu bem-estar e melhorar sua qualidade de vida. Apesar de $80 \%$ das pessoas com idade acima de 65 anos terem uma ou mais doenças crônicas e cerca da metade da população idosa ser limitada em suas atividades, os idosos, como grupo, experimentam ganhos significativos com a promoção da saúde. Estudos mostraram que os idosos são muito conscientes de sua saúde e que muitos a vêem positivamente e estão querendo adotar práticas que irão melhorar sua saúde e bem estar. Apesar de suas doenças crônicas e incapacidades não poderem ser eliminadas, esses adultos podem ser beneficiados por meio de atividades que os ajudem a manter independência e alcançar um ótimo padrão de saúde (SMELTZER \& BARE, 1998).

\section{CONCLUSÕES}

Esta pesquisa identificou a ocorrência de dor crônica em $62,5 \%$ de idosos de uma comunidade, sendo o fator relacionado mais comum o agente lesivo biológico (100\%). As evidências de maior freqüência ( $n \geq 50 \%$ ) foram o relato verbal ou codificado (100\%), capacidade alterada de continuar atividades prévias $(68 \%)$, mudanças no padrão do sono (48\%) e fadiga (52\%).

Concluímos que a dor crônica configurou-se um diagnóstico freqüente em idosos, com múltiplas características definidoras que dão sustentação segura à sua afirmação. Os fatores relacionados geralmente se referem ao processo de envelhecimento mal sucedido ou patologias características desta faixa etária.

Nesse sentido, a dor crônica nos idosos configura-se como problema de saúde coletiva, que deve ser rapidamente mapeado e atendido, em especial pelas equipes do Programa Saúde da Família, que tem como pressuposto básico 0 atendimento voltado para as reais necessidades das populações atendidas.

\section{REFERÊNCIAS BIBLIOGRÁFICAS}

ARAÚJO, L.A. de O.; SANTANA, R.F; BACHION, M.M. Mobilidade física prejudicada em idosos: Fatores relacionados e características definidoras. Rev. Brasileira de Enfermagem, v. 55, n.1, p.19-25, 2002. ATKINSON, L.D.; MURRAY, M.E. Fundamentos de Enfermagem: Introdução ao Processo de Enfermagem. Rio de Janeiro: Editora Guanabara Koogan, 1989.
BACHION, M.M. et al. Validação de conteúdo do Diagnóstico de Enfermagem "Mobilidade Física Prejudicada" em idosos. Apresentado no $51^{\circ}$ Congresso Brasileiro de Enfermagem e $11^{\circ}$ Congresso Panamericano de Enfermería. Florianópolis/SC de 02 a 07 /outubro de 1999, Livro de Resumos.p.591.

BACHION, M.M. et al. Validação clínica do diagnóstico de enfermagem: "Mobilidade Física Prejudicada" em idosos institucionalizados. ANAIS I Simpósio Internacional de Classificação da Prática de Enfermagem em Saúde Coletiva e V Simpósio Nacional de Diagnóstico de Enfermagem, João Pessoa/PB, Maio 2000. (p.40).

BERGER, L.M.; MAILLOUX-POIRIER, M. Pessoas idosas: uma abordagem global. Lisboa-Portugal: Editora Lusodidacta, 1995.

BLACK, J.M.; MATASSARIN-JACOBS, E. Luckmam \& Sorensen Enfermagem Médico-Cirúrgica: uma abordagem psicofisiológica. 4 ed. Rio de Janeiro: Editora Guanabara Koogan, 1996. 2v.

CANTERA, I.R.; DOMINGO, P.L. Guia prático de Enfermagem: Geriatria. Rio de Janeiro: Editora Mc Graw Hill; 2000.

CARVALHO FILHO, E.T. Fisiologia do Envelhecimento. In PAPALÉO NETTO, M. Gerontologia - A velhice e o envelhecimento em visão globalizada. São Paulo: Atheneu, 1999.

CRUZ, I.C.F. Implementação do Diagnóstico de Enfermagem na Unidade de Recuperação Pósanestésica - estudo piloto. Rev. Escola de Enfermagem da USP, São Paulo, v. 24 n.3, p.345-358, 1990.

CRUZ, D.A.L.M.; PIMENTA, C.A.M. Avaliação do doente com dor crônica em consulta de enfermagem: proposta de instrumento segundo diagnósticos de enfermagem. Rev.latino-am. enfermagem, Ribeirão Preto, v.7, n.3, p.49-62, jul,1999.

DUARTE, Y.A. O; DIOGO, M.J.D. Atendimento Domiciliar: Um Enfoque Gerontológico. São Paulo: Editora Atheneu, 2000.

GATTO, I.B. Aspectos Psicológicos do Envelhecimento. In PAPALÉO NETTO, M. Gerontologia - A velhice e o envelhecimento em visão globalizada. São Paulo: Atheneu, 1999.

LESSA, I. O Adulto Brasileiro e as Doenças da Modernidade - Epidemiologia das Doenças Crônicas Transmissíveis. Rio de Janeiro/ São Paulo: Editora HUCITEC/ABRASCO, 1998.

MARIN M.J.S, BARBOSA P.M.K, TAKITANE M.T. Diagnósticos de enfermagem mais freqüentes entre idosas hospitalizadas em unidade de clínica médica e cirúrgica. Rev. Bras. Enferm. Brasília: v.53, n.4, p.513523. out/dez 2000.

MORAIS, I.B; BRAGA, T.G.; SILVA, V.T.S. Princípios básicos de Enfermagem em geriatria: ações preventivas. 2 ed. Brasília-DF: Editora Gráfica Valci, 1995.

NORTH AMERICAN NURSING DIAGNOSIS ASSOCIATION. Diagnósticos de Enfermagem da N.A.N.D.A: definições e classificação - 2001-2002. Traduzido por Janne Liliane Marlena Michael. Porto Alegre: Editora Artmed, 2002. 
LACERDA, Patrícia Ferreira; GODOY, Lorany Ferreira de; COBIANCHI, Milene Gonçalves; BACHION, Maria Márcia - Estudo da 36 ocorrência de "dor crônica" em idosos de uma comunidade atendida pelo programa saúde da família em Goiânia. Revista Eletrônica de Enfermagem, v. 07, n. 01, p. 29 - 40, 2005. Disponível em www.fen.ufg.br/revista.htm

PACHECO, J.L. Práticas sociais de promoção à saúde do idoso. Arquivos de geriatria e gerontologia, v.1 n.2, Rio de Janeiro: Editora Científica Nacional, 1997.

PAPALÉO NETTO, M; PONTE, J.R. Envelhecimento: Desafio na Transição do Século. In PAPALÉO NETTO, M. Gerontologia - A velhice e o envelhecimento em visão globalizada. São Paulo: Atheneu, 1999.

PASCHOAL, S.M.P. Epidemiologia do Envelhecimento. In PAPALÉO NETTO, M. Gerontologia - A velhice e o envelhecimento em visão globalizada. São Paulo: Atheneu, 1999.

PORTO, C.C. Sinais e Sintomas In PORTO, C.C. Exame Clínico. Bases para a prática médica. Rio de Janeiro: Guanabara Koogan, 2000.
RULL, M. Abordaje multidisciplinar del dolor de espalda. Rev.Soc.Esp.Dolor, v.11, n.3, p.119-121. abr.2004.

SÁ, R. Síncope de origem cardíaca no idoso: hipotensão, bradicardia ou taquicardia? Onde está o problema? Arquivos de geriatria e gerontologia, v.1 n.2. p.73-77. Rio de Janeiro: Científica Nacional, 1997. SANTANA, R.F.; ARAÚJO, L.A. de O.; BACHION, M.M. Levantamento de "Mobilidade física prejudicada" em moradores de um condomínio residencial para idosos. Livro de Resumos do $52^{\circ}$ Congresso Brasileiro de Enfermagem, 2000, Recife-PE, 14-19 out 2000, p. 581.

SMELTZER, S.C; BARE, B.G. Tratado de Enfermagem Médico-Cirurgica. 8 ed. Rio de Janeiro: Editora Guanabara Koogan, 1998.

\section{ANEXO I}

\begin{tabular}{|c|c|c|}
\hline \multicolumn{3}{|c|}{ Roteiro para avaliação da presença de dor (avaliação de primeiro nível) } \\
\hline \multicolumn{2}{|l|}{ Nome: } & DN: \\
\hline \multicolumn{2}{|l|}{ End: } & Idade: \\
\hline Est.civil: cas( ) desc( ) & Est.civil: cas( ) desc( ) solt( ) viúvo( ) & Data da entrevista: \\
\hline \multicolumn{2}{|l|}{ Nível de escolaridade: } & Examinador: \\
\hline PA: & FR: & FC: \\
\hline \multicolumn{3}{|l|}{ Dados de Interesse: } \\
\hline \multicolumn{3}{|c|}{$\begin{array}{l}\text { HAS( ), Diabetes( ), Obesidade( ), Labirintite( ), Reumatismo( ), Osteoporose( ), Depressão( ), } \\
\text { AVC( ), Infarto( ). }\end{array}$} \\
\hline \multirow{2}{*}{\multicolumn{3}{|c|}{$\begin{array}{l}\text { Tabagismo( ) tempo: } \\
\text { Medicações em uso: } \\
\text { Dor crônica }\end{array}$}} \\
\hline & & \\
\hline Dor crônica & & \\
\hline \multicolumn{3}{|l|}{ Experiência sensorial } \\
\hline Mudanças de peso() & \multicolumn{2}{|c|}{$\begin{array}{l}\text { Perdeu peso nos últimos } 6 \text { meses? sim( ) não( ) } \\
\text { Quanto? }\end{array}$} \\
\hline $\begin{array}{l}\text { Relato verbal ou codificado( ), } \\
\text { ou evidência observada de comportamento de } \\
\text { defesa() } \\
\text { expressão facial() } \\
\text { irritabilidade(), } \\
\text { foco em si próprio() }\end{array}$ & \multicolumn{2}{|c|}{$\begin{array}{l}\text { Queixa presença de dor? } \\
\text { Tenta proteger a área dolorida com a mão? } \\
\text { Procura evitar o contato da parte do corpo que } \\
\text { tem dor? } \\
\text { Sente-se irritado? sim( ) não( ) } \\
\text { Fala o tempo todo de seus problemas, de sua } \\
\text { dor ( ) } \\
\text { Sente-se agitado? sim( ) não( ) }\end{array}$} \\
\hline Atrofia do grupo muscular envolvido() & \multicolumn{2}{|c|}{ Palpação - atrofia ( ) } \\
\hline Mudanças no padrão de sono() & \multicolumn{2}{|c|}{ Como está seu sono? Como está para dormir? } \\
\hline Fadiga() & \multicolumn{2}{|c|}{$\begin{array}{l}\text { Sente-se cansado, com pouca vontade para } \\
\text { fazer as coisas de modo geral? sim( ) não( ) }\end{array}$} \\
\hline Medo de nova lesão() & \multicolumn{2}{|c|}{$\begin{array}{l}\text { Tem medo de sentir dor em alguma outra parte } \\
\text { do corpo? }\end{array}$} \\
\hline Interação reduzida com as pessoas() & \multicolumn{2}{|c|}{$\begin{array}{l}\text { Ultimamente tem ficado muito sozinho? sim( ) } \\
\text { não( ) Por qual motivo? }\end{array}$} \\
\hline $\begin{array}{l}\text { Capacidade alterada de continuar atividades } \\
\text { prévias()Descrever o relato: }\end{array}$ & \multicolumn{2}{|c|}{$\begin{array}{l}\text { Tem que interromper o que está fazendo quando } \\
\text { tem dor? ( ) }\end{array}$} \\
\hline Respostas mediadas pelo simpático() & \multicolumn{2}{|c|}{$\begin{array}{l}\text { Temperatura corporal diminuída( ), pele fria ao } \\
\text { tato( ), mudanças na posição do corpo em } \\
\text { resposta a dor( ), hipersensibilidade dolorosa a } \\
\text { pequenos estímulos( ). }\end{array}$} \\
\hline Anorexia() & \multicolumn{2}{|c|}{$\begin{array}{l}\text { Ocorreu alguma mudança no apetite? } \operatorname{sim}(\text { ) } \\
\text { não( ) qual? Quando está com dor, consegue se } \\
\text { alimentar? sim( ) não ( ) }\end{array}$} \\
\hline
\end{tabular}




\begin{tabular}{|l|l|}
\hline & \\
\hline Fatores relacionados: & $\begin{array}{l}\text { Sofreu algum tipo de traumatismo ( ) } \\
\text { cirurgia ( ) amputação ( ) paralisia ( ) parestesia } \\
(\text { Incapacidade física() } \\
\text { psicossocial crônica() } \\
\text { Buscou serviços de saúde para avaliar/ tratar a } \\
\text { dor? sim( ) não( ) porque } \\
\text { Tem alguma coisa que pode ser feita para } \\
\text { melhorar a dor? Sim ( ) não( ) O quê? } \\
\text { Tem condições econômicas de acesso a } \\
\text { tratamento? } \\
\text { Como geralmente está seu estado emocional } \\
\text { quando você tem dor? }\end{array}$ \\
& \\
\hline & \\
\hline
\end{tabular}

Escala de Yesavage: Depressão Geriátrica (para respostas em letra maiúscula atribuir 1 ponto)

\begin{tabular}{|l|c|c|}
\hline 01. Está basicamente satisfeito com sua vida? & sim & NÃO \\
\hline 02. Abandonou muitas atividades e interesses? & SIM & não \\
\hline 03. Sente que sua vida está vazia? & SIM & não \\
\hline 04. Sente-se freqüentemente aborrecido? & SIM & não \\
\hline 05. Está bem disposto a maior parte do tempo? & $\operatorname{sim}$ & NÂO \\
\hline 06. Tem medo de que algo de mal Ihe aconteça? & SIM & não \\
\hline 07. Sente-se feliz na maior parte do tempo? & sim & NÂO \\
\hline 08. Sente-se freqüentemente sem esperanças? & SIM & não \\
\hline 09. Prefere ficar em casa a sair e ver/fazer coisas novas? & SIM & não \\
\hline 10. Acha que tem mais problemas de memória que a maioria? & SIM & não \\
\hline 11. Acredita que é maravilhoso estar vivo? & sim & NÂO \\
\hline 12. Pensa que, tal como está agora, não vale para nada? & SIM & não \\
\hline 13. Pensa que sua situação é desesperadora? & SIM & não \\
\hline 14. Sente-se cheio de energia? & sim & NÂO \\
\hline 15. Acha que a maioria das pessoas está melhor que você? & SIM & não \\
\hline
\end{tabular}

Se as respostas coincidem com as opções em maiúsculas, anotar um ponto para cada alternativa.

Avaliação: 0 a 5: normal

6 ou mais: depressão

Fonte: PORTO,C.C. Exame Clínico. Bases para a prática médica. Rio de Janeiro: Guanabara Koogan, 2000. 


\begin{tabular}{|c|c|}
\hline \multicolumn{2}{|l|}{ Avaliação clínica da dor (avaliação de segundo nível). } \\
\hline \multicolumn{2}{|l|}{ Parte I - Avaliação da dor propriamente dita: } \\
\hline \multicolumn{2}{|l|}{ 1-Sentir } \\
\hline - Está com dor agora? & $\operatorname{sim}($ ) não( ) \\
\hline \multicolumn{2}{|l|}{-Se não, quando sentiu dor pela última vez? } \\
\hline - Intensidade: escala de copos & $\begin{array}{l}\text { Qual? sem dor( ) leve( ) moderada( ) } \\
\text { intensa( ) insuportável( ) }\end{array}$ \\
\hline - A dor é: & interna( ) superficial( ) \\
\hline - A dor é: & $\begin{array}{l}\text { contínua( ) vai e vem independente de } \\
\text { qualquer coisa( ) vai e vem } \\
\text { dependendo de }\end{array}$ \\
\hline $\begin{array}{l}\text { - A dor tem início de repente ou começa devagar e vai } \\
\text { aumentando aos poucos? }\end{array}$ & início súbito( ) início insidioso( ) \\
\hline - A dor tem horário preferencial? sim( ) não( ) & Qual? manhã( ) tarde( ) noite( ) \\
\hline \multicolumn{2}{|l|}{$\begin{array}{l}\text {-Tem alguma coisa que você faz para melhorar? } \\
\operatorname{sim}(\text { ) não( ) }\end{array}$} \\
\hline \multicolumn{2}{|l|}{-O que você faz para melhorar a dor? } \\
\hline \multicolumn{2}{|l|}{ - O que não tem dado resultado no alívio da sua dor? } \\
\hline \multicolumn{2}{|l|}{ Sobre outras dores: } \\
\hline \multicolumn{2}{|c|}{ I } \\
\hline \multicolumn{2}{|c|}{$\begin{array}{l}\text {-Intensidade: sem dor( ) leve( ) moderada( ) intensa( ) insuportável( ) } \\
\text { - Tino: }\end{array}$} \\
\hline \multicolumn{2}{|l|}{ - Tipo: } \\
\hline \multicolumn{2}{|l|}{ Parte II - Impacto da dor nos padrões de respostas humanas: } \\
\hline \multicolumn{2}{|l|}{ 1- Mover } \\
\hline \multicolumn{2}{|l|}{ a-Sono } \\
\hline A dor interfere no seu sono? sim( ) não( ) & Como? \\
\hline \multicolumn{2}{|l|}{$b$-Mobilidade física } \\
\hline - A dor interfere em alguma atividade? sim( ) não( ) & $\begin{array}{l}\text { alimentar-se( ) ir ao banheiro( ) tomar } \\
\text { banho( ) vestir-se( ) caminhar( ) sair de } \\
\text { casa () levantar-se ( ) sentar-se ( ) } \\
\text { outra ( ) qual? }\end{array}$ \\
\hline $\begin{array}{l}\text { - tem limitação para mover alguma parte do corpo devido } \\
\text { a dor? } \operatorname{sim}(\text { () não( ) }\end{array}$ & Qual? \\
\hline \multicolumn{2}{|l|}{ c-Lazer } \\
\hline $\begin{array}{l}\text { Tem algum lazer ou atividade de recreação que deixou } \\
\text { de praticar devido a dor? sim( ) não( ) }\end{array}$ & Qual? \\
\hline \multicolumn{2}{|l|}{ 2- Perceber } \\
\hline \multicolumn{2}{|l|}{$\begin{array}{l}\text { - Se deixou de fazer alguma atividade devido a dor, sente } \\
\text {-se frustrado? sim( ) não( ) }\end{array}$} \\
\hline -Devido a dor, houve alteração da & $\begin{array}{l}\text { visão( ) audição( ) olfato( ) gustação( ) } \\
\text { tato( ) }\end{array}$ \\
\hline \multicolumn{2}{|l|}{ 3- Relacionar } \\
\hline \multicolumn{2}{|l|}{$\begin{array}{l}\text { - Quando você tem dor, prefere ficar mais sozinho? } \\
\operatorname{sim}(\text { ) não( ) }\end{array}$} \\
\hline - Sente-se sozinho com freqüência? sim( ) não( ) & Por que? \\
\hline \multicolumn{2}{|c|}{ OBSERVAÇÕES sobre a interação familiar e o cuidador (durante a entrevista) } \\
\hline 4- Conhecer & \\
\hline - Qual o seu probl & \\
\hline
\end{tabular}




\begin{tabular}{|c|c|}
\hline -O que faz a dor piorar? & \\
\hline 5- Comunicar & \\
\hline a- Comunicação Verbal & \\
\hline - Ficou menos comunicativo devido a dor? sim( ) não( ) & \\
\hline b- Comunicação não verbal & \\
\hline -Tristeza? sim( ) não( ) & \\
\hline -Contrariedade? sim( ) não( ) & \\
\hline - Choro? sim( ) não( ) & \\
\hline - Fácies Tranqüila? sim( ) não( ) & \\
\hline - Inquietação? sim( ) não( ) & \\
\hline -Postura de proteção? sim( ) não( ) & \\
\hline 6-Valorizar & \\
\hline - Tem preferência religiosa? sim( ) não( ) & Especifique: \\
\hline - Existem coisas espirituais importantes?sim( ) não( ) & Especifique: \\
\hline - Elas o ajudam a agüentar a dor? sim( ) não( ) & Especifique: \\
\hline 7- Escolher & \\
\hline $\begin{array}{l}\text { - Quando a dor vem o que faz para agüentá-la ou } \\
\text { melhorá-la? }\end{array}$ & \\
\hline $\begin{array}{l}\text { - Consegue fazer o que os profissionais de saúde the } \\
\text { recomendam? sim( ) não( ) }\end{array}$ & \\
\hline $\begin{array}{l}\text { A dor trouxe lhe algum problema? sim( ) não( ) } \\
\text { trabalho( ) estudos( ) família( ) outras pessoas( ) } \\
\text { sexo( ) lazer( ) financeiro( ) outros }\end{array}$ & Especifique: \\
\hline $\begin{array}{l}\text {-Tem o hábito de: } \\
\text { Ingerir bebidas alcoólicas( ) fumar cigarros( ) drogas( ) }\end{array}$ & Especificar: \\
\hline Informar as circunstâncias - especialmente se ocorrem q & indo tem dor \\
\hline 8- Trocar & \\
\hline a- Nutrição - Hidratação & \\
\hline - Apetite: & $\begin{array}{l}\text { conservado( ) diminuído( ) melhorado( } \\
\text { ) }\end{array}$ \\
\hline - Houve mudança recente no peso? sim( ) não( ) & $\begin{array}{l}\text { Quantos kg? } \\
\text { Em quanto tempo? }\end{array}$ \\
\hline $\begin{array}{l}\text { - Quando tem dor, quantos copos de líquidos ingere por } \\
\text { dia? }\end{array}$ & $\begin{array}{l}\text { Considere: água, leite, café, sucos, } \\
\text { refrigerante, etc. }\end{array}$ \\
\hline b- Eliminação Intestinal & \\
\hline - Freqüência: & \\
\hline - Consistência: & $\begin{array}{l}\text { pastosas( ) endurecidas( ) líquidas( ) } \\
\text { em síbalos( ) }\end{array}$ \\
\hline -Desconforto para evacuar? sim( ) não( ) & $\begin{array}{l}\text { dor( ) sangramento( ) } \\
\text { sensação de reto cheio( ) } \\
\text { exteriorização de hemorróidas( ) }\end{array}$ \\
\hline c- Eliminação Urinária & \\
\hline - Freqüência: & \\
\hline -Cor: & \\
\hline -Cheiro: & \\
\hline -Quantidade nas 24 horas: & $\begin{array}{l}\text { mantida( ) aumentada( ) } \\
\text { diminuída( ) }\end{array}$ \\
\hline -Desconforto urinário? sim( ) não( ) & $\begin{array}{l}\text { dor( ) sangramento( ) urgência( ) perda } \\
\text { involuntária de urina( ) retenção } \\
\text { urinária( ) diminuição de volume por } \\
\text { miç̧ão( ) aumento da freqüência( ) }\end{array}$ \\
\hline d-Respiração & \\
\hline -Durante a dor sente falta de ar? sim( ) não( ) & \\
\hline
\end{tabular}


LACERDA, Patrícia Ferreira; GODOY, Lorany Ferreira de; COBIANCHI, Milene Gonçalves; BACHION, Maria Márcia - Estudo da ocorrência de "dor crônica" em idosos de uma comunidade atendida pelo programa saúde da família em Goiânia. Revista Eletrônica de Enfermagem, v. 07, n. 01, p. 29 - 40, 2005. Disponível em www.fen.ufg.br/revista.htm

\begin{tabular}{|l|l|}
\hline $\begin{array}{l}\text { - Quando você tem dor, passa muito tempo deitado (a) ? } \\
\text { sim( ) não( ) }\end{array}$ \\
\hline $\begin{array}{l}\text {-Quando tem dor, sabe se a pressão altera? } \\
\text { sim( () não( ) }\end{array}$ & $\begin{array}{l}\text { Que valores atinge: } \\
\text { Valor usual: }\end{array}$ \\
\hline -Temperatura & \\
\hline -Quando tem dor, costuma ter febre? sim( ) não( ) & \\
\hline g-Pele & \\
\hline -A dor causou-Ihe alguma lesão? sim( ) não( ) & $\begin{array}{l}\text { hipoestesia( ) anestesia( ) } \\
\text { disestesia( ) alodínea( ) }\end{array}$ \\
\hline $\begin{array}{l}\text {-Há alguma região do corpo que a sensibilidade da pele éada? sim( ) não( ) } \\
\text { alterada }\end{array}$ & \\
\hline
\end{tabular}

Escala de copos de avaliação da intensidade da dor
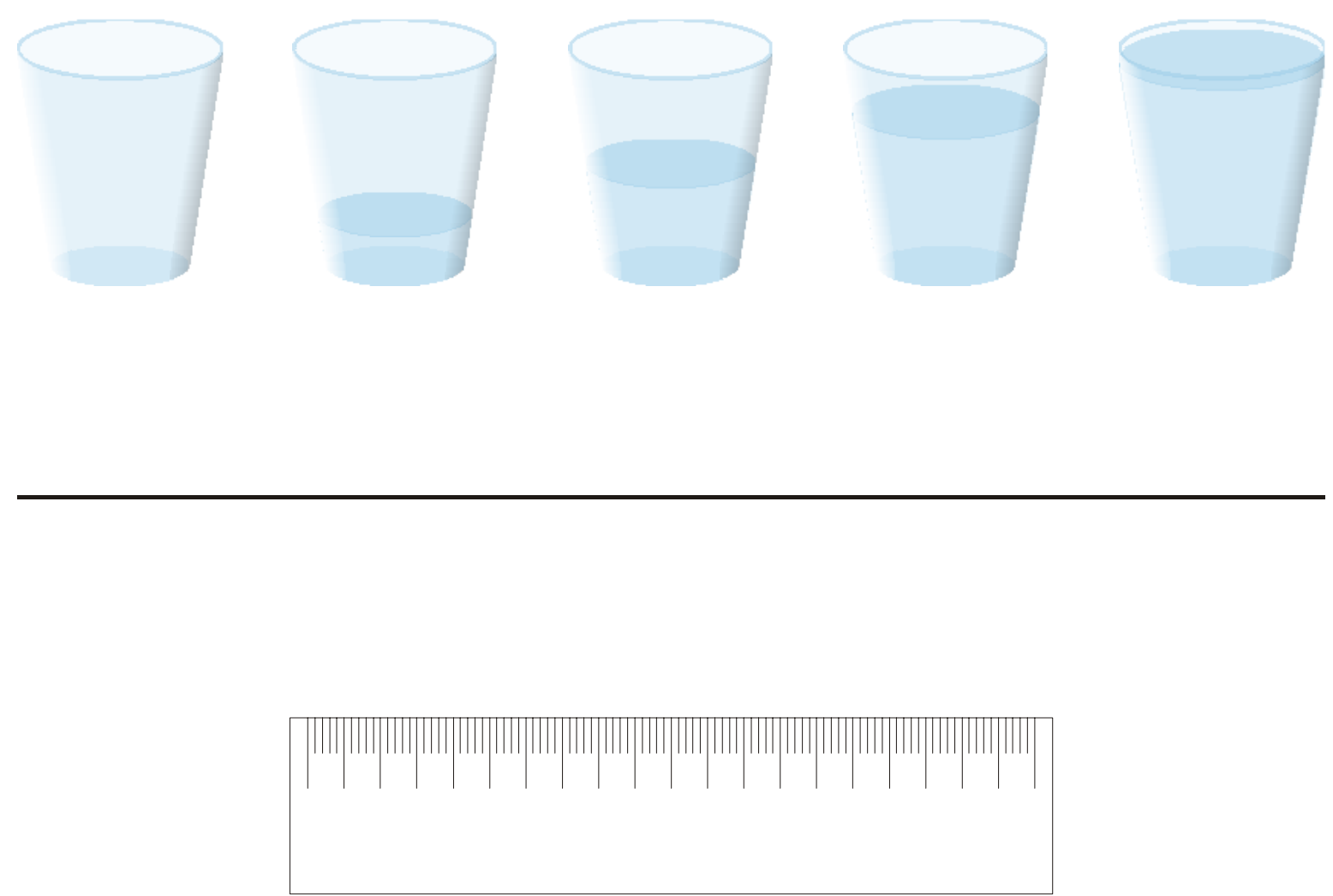

${ }^{1}$ Acadêmica do $5^{\circ}$ ano de graduação da Faculdade de Enfermagem da Universidade Federal de Goiás. patriciaufg@pop.com.br Rua dos Eucaliptos Qd.24 Lt.05 Casa 01 Setor Goiânia II Goiânia-GO 74663-270.

${ }^{2}$ Acadêmica do $5^{\circ}$ ano de graduação da Faculdade de Enfermagem da Universidade Federal de Goiás. Rua Sete de Setembro n960 Bairro Bandeirante Caldas Novas-GO 75690-000.

${ }^{3}$ Acadêmica do $5^{\circ}$ ano de graduação da Faculdade de Enfermagem da Universidade Federal de Goiás. milenegc@pop.com.br Rua D n³85 BI.A-17 Ap.202 Residencial Sonho Dourado Setor Leste Vila Nova Goiânia-GO 74635-120.

${ }^{4}$ Enfermeira. Doutora em Enfermagem. Professora da Faculdade de Enfermagem da Universidade Federal de Goiás. mbachion@fen.ufg.br Rua R-1 n72 Ap.702 Edifício Serra de Caldas Setor Oeste Goiânia-GO 74125-020 